"This is the peer reviewed version of the following article: Ferguson, C.; Inglis, S. C.; Newton, P. J.; Middleton, S.; Macdonald, P. S.; Davidson, P. M. (2017), Barriers and enablers to adherence to anticoagulation in heart failure with atrial fibrillation: patient and provider perspectives (2017) Journal of Clinical Nursing doi: 10.1111/jocn.13759 which has been published in final form at 10.1111/jocn.13759. This article may be used for non-commercial purposes in accordance with Wiley Terms and Conditions for Self-Archiving." 
DR. CALEB FERGUSON (Orcid ID : 0000-0002-2417-2216)

DR. PHILLIP NEWTON (Orcid ID : 0000-0002-5006-2037)

Received Date : 17-Jun-2016

Revised Date : 23-Jan-2017

Accepted Date : 28-Jan-2017

Article type : Original Article

\section{Barriers and enablers to adherence to anticoagulation in heart failure with atrial fibrillation: patient and provider perspectives.}

\section{Journal of Clinical Nursing}

Caleb Ferguson ${ }^{1}, \mathrm{RN}, \mathrm{PhD}, \mathrm{MHIth}, \mathrm{BScN}$;

Sally C. Inglis ${ }^{2} \mathrm{RN}, \mathrm{PhD}, \mathrm{BHSc}$ (Hons), BN;

Phillip J. Newton ${ }^{3}$ RN, PhD, BN (Hons);

Sandy Middleton ${ }^{4}$ RN, PhD;

Peter S. Macdonald ${ }^{5}$ MBBS, FRACP, PhD, MD;

Patricia M.Davidson ${ }^{6}$ RN, PhD, MEd, BA.

1. UTS Chancellor's Postdoctoral Research Fellow, Centre for Cardiovascular \& Chronic Care, University of Technology Sydney. Australia.

2. Associate Professor, Centre for Cardiovascular and Chronic Care, Faculty of Health, University of Technology Sydney. Australia.

3. Associate Professor, Centre for Cardiovascular and Chronic Care, Faculty of Health, University of Technology Sydney. Australia.

4. Professor of Nursing Research \& Director of Nursing Research Institute, St Vincent's Health Australia (Sydney) \& Australian Catholic University.

5. Medical Director, Heart Transplant Program. St Vincent's Hospital, Sydney and Victor Chang Cardiac Research Institute. Australia.

6. Professor and Dean, School of Nursing, Johns Hopkins University, Baltimore \& Professor of Cardiovascular Nursing, Centre for Cardiovascular and Chronic Care, Faculty of Health, University of Technology Sydney. Australia.

This article has been accepted for publication and undergone full peer review but has not been through the copyediting, typesetting, pagination and proofreading process, which may lead to differences between this version and the Version of Record. Please cite this article as doi: 10.1111 jocn. 13759

This article is protected by copyright. All rights reserved. 
Corresponding Author:

Dr. Caleb Ferguson RN, PhD, MHIth, BScN

UTS Chancellors Postdoctoral Research Fellow,

Centre for Cardiovascular \& Chronic Care, University of Technology Sydney. Australia

Tel +61295147235 Email; caleb.ferguson@uts.edu.au

Keywords: atrial fibrillation; stroke prevention; caregiver; medication adherence; anticoagulation.

Word count excluding references: 4546

Competing Interests: None to declare

Funding Statement: This research received no specific grant from any funding agency in the public, commercial or not-for-profit sectors.

Dr Sally C Inglis is currently supported by a Cardiovascular Research Network Life Science Research Fellowship supported by the Heart Foundation and the NSW Office for Medical Research (CR 11S 6226).

Dr Caleb Ferguson is currently supported by a National Stroke Foundation Future Leader Award and a UTS Chancellors Postdoctoral Research Fellowship.

\section{Contributorship Statement:}

CF: Study design, data collection, data analysis and interpretation, manuscript preparation.

$\mathrm{SCl}$ : Study design, data analysis and interpretation, manuscript preparation.

PJN: Study design, data analysis and interpretation, manuscript preparation.

SM: Manuscript preparation

PSM: Manuscript preparation

PMD: Study design, data analysis and interpretation, manuscript preparation.

All authors read and approved the final manuscript.

This article is protected by copyright. All rights reserved. 


\section{Aims \& Objectives}

The purpose of this study was to elucidate the barriers and enablers to adherence to anticoagulation in individuals with chronic heart failure (CHF) with concomitant atrial fibrillation (AF) from the perspective of patients and providers.

\section{Background}

CHF and AF commonly coexist and are associated with increased stroke risk and mortality. Oral anticoagulation significantly reduces stroke risk and improves outcomes. Yet, in approximately $30 \%$ of cases anticoagulation is not commenced for a variety of reasons.

\section{Design}

Qualitative study using narrative inquiry.

\section{Methods}

Data from face to face individual interviews with patients and information retrieved from healthcare file note review documented the clinician perspective. This study is a synthesis of the two data sources, obtained during patient clinical assessments as part of the Atrial Fibrillation And Stroke Thromboprophylaxis in hEart failuRe (AFASTER) Study.

\section{Results}

Patient choice and preference were important factors in anticoagulation decisions, including treatment burden, unfavourable or intolerable side effects and patient refusal. Financial barriers included cost of travel, medication cost and reimbursement. Psychological factors included psychiatric illness, cognitive impairment and depression. Social barriers included homelessness and the absence of a caregiver or lack of caregiver assistance. Clinician reticence included fear of falls, frailty, age, fear of bleeding and the challenges of multi-morbidity. Facilitators to successful prescription and adherence were caregiver support, reminders and routine, self-testing and the use of technology.

\section{Conclusions}

Many barriers remain to high risk individuals being prescribed anticoagulation for stroke prevention. There are a number of enabling factors that facilitate prescription and optimize treatment adherence. Nurses should challenge these treatment barriers and seek enabling factors to optimise therapy.

\section{Relevance to clinical practice}

Nurses can help patients and caregivers to understand complex anticoagulant risk benefit information, and act as a patient advocate when making complex stroke prevention decisions.

This article is protected by copyright. All rights reserved. 
Keywords: atrial fibrillation; heart failure; stroke prevention; caregiver; medication adherence; anticoagulation; thromboprophylaxis.

\section{Summary Box}

- Anticoagulation remains underused in clinical practice for patients with CHF and concomitant AF.

- Perceived barriers to anticoagulation should be thoroughly scrutinised by clinicians to ascertain if prescription is possible.

- Clinicians must adopt person-centred models of care. Shared decision-making allows clinicians to consider patients values, attitudes and beliefs towards anticoagulation. Including these factors alongside risk versus benefit ratios may assist in improving issues of adherence.

\section{Background}

Chronic heart failure (CHF) and atrial fibrillation (AF) commonly coexist and are associated with high mortality and risk of stroke (Lau et al. 2014). CHF and AF primarily affect older adults (Furberg et al. 1994, Ho et al. 1993). Consequently, stroke risk increases with age (Kannel et al. 1998). Anticoagulation reduces stroke risk; yet, in approximately $30 \%$ of cases treatment is not initiated for a range of reasons (Eapen et al. 2014). Adherence to anticoagulation is complex and this may be due to treatment regimens, dosing schedules and a number of sociocultural and economic factors (Ferguson et al. 2013a). Decisions to initiate anticoagulation balance a range of factors, including stroke and bleeding risk, multimorbidity and age. Prior to commencement of anticoagulation, a detailed assessment should occur. This must include careful assessment of comorbidity, the potential for treatment adherence, frailty, and cognitive and functional ability, and social supports including caregiver support (Ferguson et al. 2013b, Ferguson et al. 2014). In the elderly, rates of frailty, functional and cognitive dysfunction are more pronounced. Despite international guidelines advocating the use of validated stroke and bleeding risk stratification tools (such as $\mathrm{CH}_{2} \mathrm{DS}_{2} V A S C$ and HAS-BLED schemata), and clear consensus treatment algorithms; clinical factors particularly advancing age and frailty continue to be deterrents to optimal anticoagulant use (Brophy et al. 2004, Perera et al. 2009).

Shared decision-making is a process whereby clinicians, patients and their caregivers mutually, actively participate in making healthcare treatment decisions. This involves careful, but balanced discussions regarding risks and benefits of treatment options, and considering the individual patient's values, beliefs, preferences and own circumstances (Hoffmann et al. 2014). Patients and caregivers must be central to anticoagulation treatment decision-making (Ferguson et al. 2014, Lip \& Lane 2014). Creating mutually acceptable, shared treatment choices, has the potential to positively impact on adherence to prescribed treatment regimes.

This article is protected by copyright. All rights reserved. 


\section{Aims \& Objectives}

This study aimed to elucidate the barriers and enablers to anticoagulation in individuals with CHF with concomitant $\mathrm{AF}$ from the perspective of patients and providers.

\section{Method}

Data sources, design and setting

The study objective was achieved through an integrated synthesis of interviews and field notes collected during a 6-month cohort study. Two primary data sources were included: 1) Patient interviews during bedside clinical assessments; 2) Healthcare file note review provided a written clinician perspective. Data were extracted from healthcare records by the research team. Any written documentation was extracted that related to barriers or enablers to the prescription of anticoagulation as expressed by the provider. This study is a synthesis of the two data sources, obtained during patient clinical assessments as part of the Atrial Fibrillation And Stroke Thromboprophylaxis in hEart failure (AFASTER) Study. This study was conducted at a single site, tertiary metropolitan referral hospital in Sydney, Australia.

\section{Participants}

Potential study participants were screened for eligibility on a daily basis by a nurse researcher. Prospective consecutive participants with $\mathrm{CHF}$ and concomitant AF of any type and aetiology, consistent with international guidelines, (Camm et al. 2012, Wann et al. 2011) admitted to a cardiology ward were enrolled in the over-arching cohort study between April - October 2013. Exclusion criteria were $<18$ years of ages or AF due to reversible causes, such as thyrotoxicosis. Socio-demographic data and clinical characteristics were assessed at index hospitalisation. A sample of 144 patients with CHF and concomitant AF were included in the study. Data were generated from researcher field notes. These were obtained from both healthcare records and quotes transcribed during assessments with participants. Data were analysed and framed within the WHO's Multidimensional model of medication adherence (World Health Organisation 2003). This model provides a framework for the organisation of barriers to anticoagulation. There are five dimensions within the model which include; 1) socio-economic -;2) health system -;3) condition -;4) treatment -; and 5) patient - related factors. The findings were supported and augmented with existing scholarly literature.

\section{Ethical Considerations}

The Atrial Fibrillation And Stroke Thromboprophylaxis in hEart failure (AFASTER) study was approved by the hospital and university human ethics committees. Data included in this sub-study are an analysis of field notes collected during patient clinical assessments as part of the AFASTER cohort study. Consent was waived for baseline data collection as part of the over-arching cohort study to

This article is protected by copyright. All rights reserved. 
reduce selection bias. An opt-out approach to consent was adopted, as approved by the HREC. Participants were free to withdraw at any stage of the study. Interviews were conducted in the clinical area. Protection of data confidentiality was ensured through the de-identification and secure storage of participant records.

\section{Interview schedule}

A standardised format was followed during the clinical assessments. A relationship was established with each participant. Routinely asked open-ended questions included:

1. What helps you to remember to take your warfarin (or other anticoagulant)?

2. Tell me about your warfarin, how do you get your International Normalised Ratio (INR) checked?

3. Do you ever forget to take your medication? Tell me more about this.

4. Do you ever get any bleeding with warfarin (or other anticoagulant)?

\section{Data analysis}

Responses to open-ended questions were documented during the interview and immediately following assessments in a standardised format using the four questions above. Additional data were generated from researcher field notes and healthcare records that explained clarified and elucidated responses and also juxtaposed clinician and patient views. Data were analysed using qualitative thematic analysis. Emergent themes were categorised using a priori information from the WHO model. Themes were then framed within the model. Themes were synthesised with existing literature. Narrative inquiry was used to greater understand individuals' reasoning processes. Narrative inquiry uses stories, conversations, interviews, family stories, and life experiences, as the units of analysis to research and understand the way people create meaning in their lives as narratives (D J Cladinin \& Connelly 2000). This method allowed for the characterisation of factors where improving patient involvement may lead to better outcomes. Rigor was maintained through the presence of the research team in the clinical setting during the data collection; engaging multiple team members throughout the data analysis and checking process; and maintaining an audit trail of analysis notes.

\section{Results}

\section{Demographic and clinical characteristics}

\section{Table 1: Baseline demographics}

Full results of the AFASTER prospective cohort study have been previously published.(Ferguson et al. 2016) A summary of baseline characteristics of the cohort are provided below to contextualise the qualitative results of this study.

This article is protected by copyright. All rights reserved. 
Table 2: Key barriers from the perspective of the patient, provider \& health system

Results were summarised below within the five dimensions to the World Health Organisation's multidimensional adherence model. These included socioeconomic, health care system, condition, treatment and patient related factors (World Health Organisation 2003). We have included relevant discussion to contextualise individual results and components of factors influencing decision making where appropriate within the results section of this paper. A broader discussion is included within the subsequent section of this paper to provide overall context of the full results of this study.

\section{Treatment-related factors}

\section{Familiarity of burden}

During the participant clinical assessments, the burden of warfarin was immediately recognisable. One patient exclaimed ... "It's a nuisance!" - referring to warfarin therapy. This combined with the often lifetime duration of therapy increases the complexity of issues of adherence and compliance. Conversely, a 90-year old gentleman explained: "Aww I've been taking it [warfarin] for over 20 years now, so I suppose I'm used to it" (0069). This helps to understand, that with time patients may become more familiar with their therapy, requirements for routine testing and dose adjustment as treatment endures.

\section{Carelessness with adherence to treatment requirements}

Some patients admitted non-adherence to treatment requirements, such as having regular INR testing when indicated: "I get my bloods checked every 2 - 3 weeks, I know I should go more though, you know" (0069) and another... "I've got to admit I'm a bit slack on the INR testing" (0056). Further, a 74-year old male patient explained about how he was careless at times when managing his medications at home: "Sometimes I take $1-2$ weeks to refill my scripts, just for the non-essential ones, you know" (0058). Yet, in contrast, some patients found self-monitoring, including point of care testing helpful. "I go to my GP weekly for my finger prick test" (0045). Patient self-testing was also found to be useful with younger patients. "I take it [INR] twice a week at home. My GP recommended I purchase" - Referring to INR self-checking and device purchase (0119) - 20 year old female patient. Studies have shown patients and caregiver can successfully be trained in INR selftesting in approx. 2 - 4 weeks, (Dolor et al. 2010) highlighting that all patients should be given the opportunity to learn how to self-test, and if competent should be given the opportunity to continue with home self-testing (Dolor et al. 2010). Patient self-management has been found to lead to more stable anticoagulant therapy and subsequently lower rates of adverse stroke and bleeding events (Horstkotte \& Piper 2004).

This article is protected by copyright. All rights reserved. 


\section{Socio-economic factors}

\section{Financial burden}

Financial factors, such as hardship may impact patient adherence to anticoagulation. These include funding frequent travel to clinics, for check-ups and routine blood tests.(Ferguson et al. 2013a) A 79year-old female patient explained how she was able to obtain support from a government scheme: "It's expensive to travel to all the appointments, but my GP got me these cab-charge things, you get half of your fare paid, which is handy" (0020). Cost-related medication non-adherence (CRN) is a common problem, particularly for the elderly within multi-morbidity, often on complex medication regimes. In our cohort, the mean number of prescribed medications was 11.

\section{Condition-related factors}

\section{Mental health considerations}

Adherence within the context of heart failure in the setting of psychiatric disorder is complex. Current initiatives and guidelines do not consider this. A physician documenting in a patient's medical record with a history of schizophrenia writes: "Refuses to take regular medications, only takes frusemide" (0107). When this patient was asked about how he manages his medications at home and medication adherence, he replied, "They are trying to poison me, you know!" (0107). The clinical assessment was ceased following this statement and the participant not deemed suitable for inclusion in the cohort study. This patient was later readmitted to hospital and found to be in decompensated heart failure secondary to poor medication compliance. Issues of medication nonadherence in CHF \& AF and mental illness are neither well-understood nor managed in clinical practice. This is similar to research by Walker et al (2011) who found that patients with mental health conditions and AF were less likely to have adequate management for their AF than those without (Walker et al. 2011). Individually tailored environmental supports can improve medication adherence and outcomes in patients with mental health conditions (Velligan et al. 2008). Further research is urgently needed to direct interventions to improve care for those with AF and mental health conditions.

\section{Depression and adherence}

A nursing note entry in a patient's health record stated: "patient saying doesn't want medications, wants to sleep, and wants to die". A subsequent medical entry further detailed... "Depressed moodwants to go home. Refusing medications, Plan: Palliative care review" (0141)

In the setting of coronary heart disease, depression is associated with medication non-adherence (Gehi et al. 2005). However, systematic review evidence demonstrates that the relationship between depression and medication adherence in CHF is inconsistent (Oosterom-Calo et al. 2012). The above participant was not prescribed anticoagulation upon discharge. The moral and ethical considerations regarding the continuation of anticoagulation during end-of-life are difficult. Treatment with warfarin may be deemed futile and minimising the number of medications

This article is protected by copyright. All rights reserved. 
prescribed and achieving comfort may be the most appropriate care goals. This patient later was transferred to hospice care and passed away with the support of the palliative care service. Understanding and balancing a patient's needs and wants is important and this is an essential component in making treatment choices and shared decision-making around anticoagulation, and toward achieving person-centred care.

\section{Health-system related factors}

\section{Frailty and fears of falls}

Functional decline is a common consequence of both CHF and AF (Marzona et al. 2012). A study by Bajorek et al (2002) identified that warfarin was being withheld in AF patients $>80$ years for reasons other than recognised contraindications and is potentially underused in this target population (Bajorek et al. 2002). In our study, a medical officer details his rationale for non-prescription due to frailty and age. "Although scoring 3 on $\mathrm{CHADS}_{2}$ (CHF, Hypertension \& Age) given her age, frailty and previous $\mathrm{Gl}$ bleed it was felt that in her case risks would outweigh benefits of anticoagulation, thus she was commenced on clopidogrel alone (vague history of Gl bleed on aspirin)." 94-year-old female patient with supportive family, seeking respite care on discharge from hospital (0125).

Olesen et al (2011) emphasises that with advanced ageing, the risk of stroke increases and oral anticoagulation should not be avoided in elderly patient because of concerns regarding bleeding risk and age alone (Camm et al. 2010, Marinigh et al. 2010, Olesen et al. 2011). The authors highlight that the decision to anticoagulate should always be based on careful evaluation of the balance between stroke risk vs. bleeding risk. During a review of medications, documented on a discharge summary: "Warfarin ceased this admission due to high falls risk and malignancy. Commenced on aspirin." (0124) An 84-year-old female patient.

Sellers et al (2011) suggest that an elderly patient taking warfarin would have to experience approximately 300 falls per year for the risk of bleeding complications from falling to outweigh the benefits for prevention of embolic stroke. This finding emphasises that clinician education is needed with regard to the actual risk that falls pose to patients receiving anticoagulation (Sellers \& Newby 2011). Similar research conducted by Man-Son-Hing et al (1999) determined that patients taking warfarin must fall approximately 295 times in a year for warfarin not to be optimal therapy. These authors suggested that a patient's propensity to fall should not be an important factor in decision making on anticoagulation (Man-Son-Hing et al. 1999). Yet, the myth of falls as a factor to withhold anticoagulation, and that the risk of bleeding in this scenario would outweigh the benefits, remains in clinical practice today, as demonstrated from the quote provided above.

In a large real-world cohort study (Olesen et al, 2011) investigating the use of aspirin and oral anticoagulation in patients with $\mathrm{AF}$, Olesen and co-authors reported that aspirin was not protective at any level of stroke risk, and was not safe or effective for stroke prevention in AF (Olesen et al. 2011). To this point, the now focused update of the ESC Guidelines for the management of AF (Camm et al, Euro Heart Rhythm Association, 2012) advocate that "The evidence for effective stroke prevention with aspirin in AF is weak, with a potential for harm" and "given the availability of NOACs, the use of antiplatelets for stroke prevention in AF should be limited to the few patients who refuse

This article is protected by copyright. All rights reserved. 
any form of oral anticoagulation". A study conducted by Perera et al (2010) identified that frail older people with AF are significantly less likely to receive warfarin than non-frail. Elderly frail people with AF appear to be more vulnerable to adverse clinical outcomes with and without anticoagulation (Perera et al. 2009).

\section{Fears of bleeding}

Bleeding remains the most feared adverse event amongst clinicians when making decisions about anticoagulant choice in AF (Pugh et al. 2011). The biggest fear is that of massive catastrophic haemorrhage, particularly intracranial or gastro-intestinal, with associated increased morbidity and mortality. Documented in a letter by cardiologist regarding a male patient: "He is not on warfarin because of GI bleeding which is related to the cancer. He is not keen to be re-trialled with it". Further - Cardiologist, Jan 2013 "I am not keen to have him on warfarin or dabigatran because of significant bleeding from warfarin in the past and the dangers associated with dabigatran, which has made us a lot less interested in using it over the past 12 months."

\section{Patient-related factors}

\section{Cognitive Dysfunction}

Cognitive dysfunction is a common consequence of AF and CHF (Cameron et al. 2010, Marzona et al. 2012, Pressler 2008). This may be an effect of micro thrombi, hypo-perfusion or other pre-existing health condition such as dementia. A MMSE score $<23$ is independently associated with suboptimal INR control and likely poor time in therapeutic range (TTR) (van Deelen et al. 2005). This needs to be considered when making judicious treatment decisions about anticoagulation in this primarily elderly population. Cognitive dysfunction is a complex challenge for those whom clinicians seek to treat with anticoagulation and often the cooperation and support of caregivers is vital to making decisions in this circumstance. The Montreal Cognitive Assessment (MOCA) is a valuable tool to identify patients with AF who may need additional support to maintain optimal TTR and effective anticoagulation control (Flaker et al. 2010).

During our medical file reviews, a clinician documented in the notes of this 88-year-old lady who lived alone: "Refuses to use medication aide. Has a history of mild cognitive impairment." The patient explained further when assessed... "I like to know what each one is for. I put the next day's one out"... Stating... "I never forget!... now what's my routine..." (0117). This highlights the complexity of the situation. Familiarity and routine are important factors in medication taking. Evidence supports that living alone is a risk factor for increased morbidity and mortality (Case et al. 1992). Medication aides are helpful, however may not be suitable for everyone.

Current guidelines neglect to address the complexity of multi-morbidity. AF is unlikely to be a singular health complaint in a geriatric population. Patients with AF are likely to be elderly with multiple comorbidities. Given that AF risk increases with age, guidelines must move to address the

This article is protected by copyright. All rights reserved. 
issue that AF often exists with other conditions. There are limited interventions that provide support for patients with $A F$ and cognitive dysfunction to adequately manage their anticoagulation. Novel oral anticoagulants may offer promise for this population, as use of these drugs would minimise the need for routine monitoring and dose adjustment.

\section{Visual Impairment}

When this patient was asked about barriers to heart failure self-management, specifically monitoring a daily weight; in response to the question of "Do you weigh yourself every day?", she replied "I have macular degeneration and I can't see the numbers!" (0120). Similarly, this was thought to be an issue when managing her medications. Older people are more likely to experience age-related changes such as impaired vision and manual dexterity issues when opening (often difficult) childproof medication packaging (Gazmararian et al. 2006).

\section{Social support}

\section{Homelessness}

Clinicians frequently documented their rationale for the non-prescription of anticoagulation in the setting of AF and CHF. A physician of a 65 -year-old homeless man detailed a consultation with a patient in his medical record: "Warfarin and Clexane [Enoxaparin] have been ceased following consultation with patient $X$ re: likelihood of medication compliance. Patient happy not to continue with anticoagulant therapy." (0054). Homelessness creates a challenge for the healthcare system and how we provide primary care services to the vulnerable. Homeless people are not often able to rest or recover, nor able to find a safe place to store and manage their vital medications. Continuity of care is problematic. Many of our current systems fail to meet the needs of the homeless with AF and care is well below standard (McCary \& J 2005). Homelessness should not be a barrier to anticoagulation in 2016. This emphasizes the need to develop innovative management strategies that are individually tailored to meet the needs of patients.

\section{Caregiver role}

The role of the caregiver is under recognised by healthcare professionals in clinical practice (Ferguson et al. 2014). Caregivers play a vital role in supporting patients with AF, particularly those who may have functional decline or cognitive dysfunction as a consequence of their AF. During the assessments an 83-year-old man explained how he relies on his sister for support when managing his medications at home and how this is important for him: "My sister looks after all that, if it was up to me l'd have to put a big sign up to remember" (0112). Caregivers play an important role in anticoagulation management. Examples of caregiver assistance range from verbal reminders transport to refill prescriptions and attend anticoagulation clinics, to physical assistance to read medication bottles and take tablets. Further to this, the importance of caregiver respite was highlighted. "If my sister goes away, I get the respite. I get Meals on Wheels then" (0112). Davidson

This article is protected by copyright. All rights reserved. 
et al (2013) identified that there is significant burden placed on caregivers of people with nonmalignant conditions, caring for individuals in the community over extended periods (Davidson et al. 2013). Health professionals must recognise this burden, and develop family and person centred interventions to address and reduce burden.

\section{Importance of routine and reminders}

Many patients highlighted the theme of developing and maintaining routine and reminder systems. An 87-year-old female patient highlighted the importance of routine in self-care management: "It's habit. Every morning I just check my blood pressure" (0109). Caregiver assistance in medication management and routine was explained in more detail: "Once a week, Sunday morning - my husband helps me refill my dosett box" "XXX helps me remember" "Me and XXX do it on a Sunday morning, he helps me sort the tablets out the boxes into the thing" "XXX helps me remember" (0092). "First I put the plants in vases, then the tablets and make the porridge and then the swim" highlighting the importance of routine in assisting with medication adherence. 72-years-old lady; still manages to swim 5 times per week in the morning (0108).

Technology to assist with reminder and adherence to medication regimes was found to be helpful by this 74-years-old female patient. "The kids have set an alarm on that thing twice a day for me" refers to her smartphone (0113). "You got to have a system, or else you'd be doubling up on lots" (0118) - highlighting the importance of developing a 'system' and a routine in medication taking. Systematic review data suggest that interventions that include convenient care, information, reminders, self-monitoring, reinforcement, counselling, family or psychological interventions, telephone follow up or supportive care, or a combination of the aforementioned may be effective for long term care, such as in AF. However, these interventions have been shown to produce at best modest improvements in adherence or treatment outcomes (Haynes et al. 2008).

\section{Discussion}

The results of this study are similar to research conducted by Eapen et al (2014), whereby one third of eligible patients with $\mathrm{CHF}$ and $\mathrm{AF}$ were not prescribed warfarin therapy at discharge from a heart failure hospitalisation (Eapen et al. 2014). A systematic review conducted by Ogilvie et al (2010) report oral anticoagulation treatment levels below 60\% (range $19-81 \%$ ) and demonstrates the underuse of OAC therapy for patients with an elevated stroke risk (Ogilvie et al. 2010).

A recent systematic review highlights that nurse managed protocols are effective in the outpatient management of a range of chronic conditions including diabetes, hypertension and hyperlidipaemia. A nurse-led intervention was associated with improvement in biomarkers including a decrease in $0.4 \%$ of $\mathrm{HbA1c}$ in diabetes, a reduction in SBP of $3.68 \mathrm{mmHg}$ and DBP of $1.56 \mathrm{mmHg}$ in hypertension management, and a decrease of total cholesterol by $0.24 \mathrm{mmol} / \mathrm{L}$ and $\mathrm{LDL}$ cholesterol by 0.31 $\mathrm{mmol} / \mathrm{L}$ (Shaw et al. 2014).

Further, nurse-led models of care in AF have also shown promise. A recent RCT in Europe examined nurse-led care intervention of protocol-based, software supported integrated chronic care, supervised by a cardiologist. This innovative model of care was superior to usual care, with decreased rate of hospitalization and mortality (Hendriks et al. 2012). These findings further support a team approach that adopts nurse-managed protocols can have positive effects on the

This article is protected by copyright. All rights reserved. 
management of individuals with chronic diseases including diabetes, hypertension, hyperlipidemia and atrial fibrillation. Developing nurse-led programs appears to be an innovative method of optimizing access for patients with clinicians. Nurse-led chronic care models have the opportunity to improve self-management, and fully engage the individual and their caregiver in the shared-decision making process (Ferguson et al. 2014).

\section{Patient preference, choice and shared decision-making}

Results from a study conducted by Dantas et al (2004) identified that patients have limited input into the decision to commence anticoagulation, and that patients lack understanding of the risks and benefits associated with treatment (Dantas et al. 2004). Patients prefer treatment discussions to include individual risk-based information, in contrast to generic population risk-based information (Edwards et al. 2002). Empowering patients to make informed decisions based on risks and benefits stands to improve patient knowledge about treatment (Hoffmann et al. 2014). Previous research has highlighted both the condition and treatment knowledge deficit that exists for patients receiving anticoagulation (Tang et al. 2003). Knowledge insufficiency is often a determinant itself of poor time in the therapeutic range. Clinicians need to thoroughly explain the risks and benefits of each treatment. An individual risk profile should be presented to the patient, and tailored and presented in a way to the patient, whereby the information is meaningful and understood. Pictorial faces and images may be helpful to describe risk to those with limited health literacy (Goodyear-Smith et al. 2008). This may improve patients and caregivers knowledge and empower them to make informed decisions about available treatment choices. Taking time to understand patient values and preferences towards treatments is essential and should not be overlooked. This may help to increase adherence to treatment regimens (Lip \& Lane 2014).

\section{Limitations}

This study has some limitations. Firstly, the majority of the quotes selected for inclusion in this paper originated from informal bedside interviews, whilst conducting clinical assessments as part of a larger cohort study. Whilst the interviews were not audiotaped, or transcribed verbatim, this is a pragmatic method of data collection in healthcare research (Halcomb \& Davidson 2006). The use of field notes documented during or immediately post interview has previously been reported as having greater importance and utility, than the sole use of audiotaping and verbatim transcription (Halcomb \& Davidson 2006). Though the researcher attempted to create an open environment and ask standardised questions, there may have been bias introduced in how the questions were delivered. However, the quotes obtained were transcribed during the assessment and field notes about the assessment were gathered and taken immediately post assessment. The researcher reflected on these data and augmented the findings with supporting existing literature. This study reflects a contemporary narrative of the barriers and enablers to anticoagulation for patients with $\mathrm{CHF}$ and $\mathrm{AF}$.

This article is protected by copyright. All rights reserved. 


\section{Conclusion}

$\mathrm{CHF}$ and $\mathrm{AF}$ are burdensome conditions that habitually coexist. In this study, warfarin was the most frequently used type of anticoagulant and this remains a problematic drug for many clinicians, patients and caregivers. Almost one third of participants were not prescribed anticoagulation on discharge from hospital. The results of this study suggest that there remain many barriers to patients receiving anticoagulation. Concerns remain amongst clinicians with regards to falls and bleeding events. The barriers highlighted in this sub-study were frailty, age, cognitive dysfunction, homelessness, mental illness, vision impairment, and depression. Facilitators to successful prescription and adherence were caregiver support, reminders and routine, self-testing and the use of technology.

\section{Relevance to clinical practice}

This study has demonstrated that many barriers still remain to the prescription of anticoagulation for stroke prevention in high risk cardiovascular patients. Further, we have also elucidated a number of encouraging and enabling factors that assist in optimising adherence to prescribed therapy. Nurses must provide advocacy for the patient to increase understanding of the risks and benefits of different treatments, and offer a solution focused approach to challenge and address key barriers to prescription in practice.

\section{References}

Bajorek BV, Krass I, Ogle SJ, Duguid MJ \& Shenfield GM (2002): The impact of age on antithrombotic use in elderly patients with non-valvular atrial fibrillation. Australasian Journal on Ageing 21, 36-41.

Brophy MT, Snyder KE, Gaehde S, Ives C, Gagnon D \& Fiore LD (2004): Anticoagulant Use for Atrial Fibrillation in the Elderly. Journal of the American Geriatrics Society 52, 1151-1156.

Cameron J, Worrall-Carter L, Page K, Riegel B, Lo SK \& Stewart S (2010): Does cognitive impairment predict poor self-care in patients with heart failure? European Journal of Heart Failure 12, 508-515.

Camm AJ, Kirchhof P, Lip G, Schotten U, Savelieva I, Ernst S \& et al (2010): Guidelines for the management of atrial fibrillation: the task force for the management of atrial fibrillation of the European Society of Cardiology (ESC). European Heart Journal 31, 2369-2429.

Camm AJ, Lip GYH, De Caterina R, Savelieva I, Atar D, Hohnloser SH, Hindricks G \& Kirchhof P (2012): 2012 focused update of the ESC Guidelines for the management of atrial fibrillation. European Heart Journal 33, 2719-2747.

Case RB, Moss AJ, Case N, McDermott M \& Eberly S (1992): Living alone after myocardial infarction: Impact on prognosis. JAMA 267, 515-519.

D J Cladinin \& Connelly FM (2000) Narrative inquiry; experience and story in qualitative research. Jossey-Bass, San Francisco CA.

Dantas G, Thompson B, Manson J, Tracy CS \& Upshur R (2004): Patients' perspectives on taking warfarin: qualitative study in family practice. BMC Family Practice 5, 15.

Davidson P, Abernethy A, Newton P, Clark K \& Currow D (2013): The caregiving perspective in heart failure: a population based study. BMC Health Services Research 13, 342.

This article is protected by copyright. All rights reserved. 
Dolor RJ, Ruybalid RL, Uyeda L, Edson RG, Phibbs C, Vertrees JE, Shih M-C, Jacobson AK, Matchar DB \& Investigators TS (2010): An evaluation of patient self-testing competency of prothrombin time for managing anticoagulation: pre-randomization results of VA Cooperative Study \#481-The Home INR Study (THINRS). Journal of Thrombosis and Thrombolysis 30, 263-275.

Eapen ZJ, MI X, Qualls LG, Hammill BG, Fonarow GC, Turakhia MP, Heidenreich PA, Peterson ED, Curtis LH, Hernandez AF \& Al-Khatib SM (2014): Adherence and persistence in the use of warfarin after hospital discharge among patients with heart failure and atrial fibrillation. Journal of Cardiac Failure 20, 23-30.

Edwards A, Elwyn G \& Mulley A (2002): Explaining risks: turning numerical data into meaningful pictures. BMJ 324, 827-830.

Ferguson C, Inglis SC, Newton PJ, Middleton S, Macdonald PS \& Davidson PM (2013): Atrial fibrillation and thromboprophylaxis in heart failure: the need for patient-centered approaches to address adherence. Vascular health and risk management 9, 3-11.

Ferguson C, Inglis SC, Newton PJ, Middleton S, Macdonald PS \& Davidson PM (2014): The caregiver role in thromboprophylaxis management in atrial fibrillation: a literature review. European Journal of Cardiovascular Nursing 14(2), 98-107.

Ferguson C, Inglis SC, Newton PJ, Middleton S, Macdonald PS \& Davidson PM (2016): Multimorbidity, frailty and self-care: important considerations in treatment with anticoagulation drugs. Outcomes of the AFASTER study. Eur J Cardiovasc Nurs.

Flaker GC, Pogue J, Yusuf S, Pfeffer MA, Goldhaber SZ, Granger CB, Anand IS, Hart R, Connolly SJ \& Investigators ftAFCTWIfPoVE (2010): Cognitive Function and Anticoagulation Control in Patients With Atrial Fibrillation. Circulation: Cardiovascular Quality and Outcomes 3, 277283.

Furberg CD, Psaty BM, Manolio TA, Gardin JM, Smith VE \& Rautaharju PM (1994): Prevalence of atrial fibrillation in elderly subjects (the Cardiovascular Health Study). The American Journal of Cardiology 74, 236-241.

Gazmararian JA, Kripalani S, Miller MJ, Echt KV, Ren J \& Rask K (2006): Factors Associated with Medication Refill Adherence in Cardiovascular-related Diseases: A Focus on Health Literacy. Journal of General Internal Medicine 21, 1215-1221.

Gehi A, Haas D, Pipkin S \& Whooley M (2005): Depression and Medication Adherence in Outpatients With Coronary Heart Disease: Findings From the Heart and Soul Study. Archives of Internal Medicine 165, 2508-2513.

Goodyear-Smith F, Arroll B, Chan L, Jackson R, Wells S \& Kenealy T (2008): Patients Prefer Pictures to Numbers to Express Cardiovascular Benefit From Treatment. The Annals of Family Medicine 6, 213-217.

Halcomb EJ \& Davidson PM (2006): Is verbatim transcription of interview data always necessary? Appl Nurs Res 19, 38-42.

Haynes R, Ackloo E, Sahota N, McDonald H \& Yao X (2008): Interventions for enhancing medication adherence. Cochrane Database of Systematic Reviews.

Hendriks JML, deWit R, Crijns HJGM, Vrijhoef HJM, Prins MH, Pison LAFG, Blaauw Y \& Tieleman RG (2012): Nurse-led care vs usual care for patients with atrial fibrillation. European Heart Journal 33, 2692-2699.

Ho KK, Pinsky JL, Kannel WB \& Levy D (1993): The epidemiology of heart failure: the Framingham Study. J Am Coll Cardiol 22, 6a-13a.

Hoffmann TC, Legare F, Simmons MB, McNamara K, McCaffery K, Trevena L, Glasziou P \& Del Mar CB (2014): Shared decision making: what do clinicians need to know and why should they bother. Medical Journal of Australia 201, 35-39.

Horstkotte D \& Piper C (2004): Improvement of oral anticoagulation therapy by INR selfmanagement. Journal of Heart Valve Disease 13, 335-338.

This article is protected by copyright. All rights reserved. 
Kannel WB, Wolf PA, Benjamin EJ \& Levy D (1998): Prevalence, incidence, prognosis, and predisposing conditions for atrial fibrillation: population-based estimates. Am J Cardiol 82, 2n-9n.

Lau YC, Lane DA \& Lip GYH (2014): Atrial Fibrillation and Heart Failure: A Bad Combination. The American Journal of Cardiology.

Lip GYH \& Lane DA (2014): Patient's values and preferences for stroke prevention in atrial fibrillation: balancing stroke and bleeding risk with oral anticoagulation. Thrombosis and Haemostasis 111(3), 381-3.

Man-Son-Hing M, Nichol G, Lau A \& Laupacis A (1999): Choosing antithrombotic therapy for elderly patients with atrial fibrillation who are at risk of falls. Arch Intern Med 159, 677-685.

Marinigh R, Lip GYH, Fiotti N, Giansante C \& Lane DA (2010): Age as a risk factor for stroke in atrial fibrillation patients. Journal of American College of Cardiology 56, 827-837.

Marzona I, O'Donnell M, Teo K, Gao P, Anderson C, Bosch J \& Yusuf S (2012): Increased risk of cognitive and functional decline in patients with atrial fibrillation: results of the ONTARGET and TRANSCEND studies. Canadian Medical Association Journal.

McCary JM \& J OCJ (2005): Health, Housing and the Heart: Cardiovascular Disparities in Homeless People. Circulation 111, 2555-2556.

Ogilvie IM, Newton N, Welner SA, Cowell W \& Lip GYH (2010): Underuse of Oral Anticoagulants in Atrial Fibrillation: A Systematic Review. The American Journal of Medicine 123, 638-645.

Olesen JB, Lip GYH, Hansen PR, Lindhardsen J, Ahlehoff O, Andersson C, Weeke P, Hansen ML, Gislason GH \& Torp-Pedersen C (2011): Bleeding risk in real world patients with atrial fibrillation: Comparison of two established bleeding prediction schemes. J Thromb Haemost 9, 1460-1467.

Oosterom-Calo R, van Ballegooijen A, Terwee C, te Velde S, Brouwer I, Jaarsma T \& Brug J (2012): Determinants of adherence to heart failure medication: a systematic literature review. Heart Failure Reviews 18, 409-427.

Perera V, Bajorek BV, Matthews S \& Hilmer SN (2009): The impact of fraility on the utilisation of antithrombotic therapy in older patients with atrial fibrillation. Age and Ageing 38, 156-162.

Pressler SJ (2008): Cognitive functioning and chronic heart failure: a review of the literature (2002July 2007). The Journal of cardiovascular nursing 23, 239-249.

Pugh D, Pugh J \& Mead GE (2011): Attitudes of physicians regarding anticoagulation for atrial fibrillation: a systematic review. Age and Ageing.

Sellers MB \& Newby KL (2011): Atrial fibrillation, anticoagulation, falls risk, and outcomes in elderly patients. Am Heart J 161, 241-246.

Shaw RJ, McDuffie JR, Hendrix CC, Edie A, Lindsey-Davis L, Nagi A, Kosinski AS \& Williams Jr JW (2014): Effects of Nurse-Managed Protocols in the Outpatient Management of Adults With Chronic Conditions. Annals of Internal Medicine 161, 113-121.

Tang E, Lai C, Lee K, Wong R, Cheng G \& Chan T (2003): Relationship between patient's warfarin knowledge and anticoagulation control. The Annals of Pharmacotherapy 37.

van Deelen BAJ, van den Bemt PMLA, Egberts TCG, van't Hoff A \& Maas HAAM (2005): Cognitive Impairment as Determinant for Sub-Optimal Control of Oral Anticoagulation Treatment in Elderly Patients with Atrial Fibrillation. Drugs \& Aging 22, 353-360.

Velligan DI, Diamond PM, Mintz J, Maples N, Li X, Zeber J, Ereshefsky L, Lam Y-WF, Castillo D \& Miller AL (2008): The Use of Individually Tailored Environmental Supports to Improve Medication Adherence and Outcomes in Schizophrenia. Schizophrenia Bulletin 34, 483-493.

Walker GA, Heidenreich PA, Phibbs CS, Go AS, Chiu VY, Schmitt SK, Ananth L \& Frayne SM (2011): Mental illness and warfarin use in atrial fibrillation. The American Journal of Managed Care 17, 617-624.

Wann L, Curtis A, January C, Ellenbogen K, Lowe J, Estes N, Page R, Ezekowitz M, Slotwiner D, Jackman W, Stevenson W \& Tracy C (2011): 2011 ACCF/ AHA/ HRS focused update on the management of patients with atrial fibrillation: a report of the American College of

This article is protected by copyright. All rights reserved. 
Cardiology Foundation/ American Heart Association Task Force on Practice Guidelines.

Circulation 123, 104-123.

World Health Organisation (2003) Adherence to Long Term Therapies: Evidence for Action. World Health Organisation, Geneva, Switzerland.

\begin{tabular}{|l|l|}
\hline Variable & $\%$ \\
\hline Age (yrs, mean, SD, range) & $72 \pm 16.4(19-94)$ \\
\hline Sex $(n=$ male) & $65 \%$ \\
\hline Living alone $(n=28)$ & $33 \%$ \\
\hline NHYA Class II-III ( $n=62)$ & $61 \%$ \\
\hline LVEF <45\% (\%) & $59 \%$ \\
\hline Charlson Comorbidity Index Score (mean, SD) & $3.9 \pm 2.1$ \\
\hline Frailty status (\%, $n=$ frail) (92 participants included) & $63 \%$ \\
\hline $\mathrm{CHA}_{2} \mathrm{DS}$ VASc (Stroke risk) Score (mean, SD) & $4.3 \pm 1.9$ \\
\hline HASBLED (Bleeding risk) Score (mean, SD) & $2.9 \pm 1.6$ \\
\hline Number of medications on discharge (mean, SD) & $11 \pm 4$ \\
\hline Prescription of warfarin on discharge ( $n=77)$ & $58 \%$ \\
\hline Prescription of an antiplatelet on discharge $(n=55)$ & $41 \%$ \\
\hline Prescription of a novel anticoagulant at discharge $(n=5)$ & $4 \%$ \\
\hline
\end{tabular}

\section{Results: Key barriers to anticoagulation}

- Burden of routine monitoring is unfavourable or intolerable

- Cannot afford medication or travel to clinic or appointments

- Homelessness

- Psychiatric illness

- Patient refusal

- Fear of falls

- Frailty

- Fear of bleeding

- Clinician apprehension

- Age

- Cognitive impairment

- Multi-morbidity

- Lack of caregiver assistance

- Depression

- End-of-life considerations

This article is protected by copyright. All rights reserved. 